\title{
Effects of probucol on angiotensin II-induced BMP-2 expression in human umbilical vein endothelial cells
}

\author{
MING ZHANG*', JIAN WANG*, JING-HUA LIU, SHU-JUAN CHEN, BIN ZHEN, \\ CHANG-HUA WANG, HUA HE and CHEN-XI JIANG
}

Department of Cardiology, Beijing Anzhen Hospital, Capital University of Medical Sciences, Beijing 100029, P.R. China

Received May 4, 2012; Accepted August 29, 2012

DOI: $10.3892 / \mathrm{mmr} .2012 .1145$

\begin{abstract}
Bone morphogenetic protein-2 (BMP-2) participates significantly in vascular development and pathophysiological processes. Angiotensin II (AngII) has been demonstrated to be critical in the initiation and progression of atherosclerosis. However, the effects of AngII on BMP-2 expression and of probucol on the AngII-induced BMP-2 expression in human umbilical vein endothelial cells (HUVECs) are unknown. The aim of our study was to investigate these effects. HUVECs were cultured and stimulated with various agents. The total superoxide dismutase (SOD) activity and the concentrations of malondialdehyde (MDA) and BMP-2 were measured by standard methods. Northern blotting was used to detect the expression of BMP-2 mRNA. The activation of NF- $\kappa \mathrm{B}$ in the HUVECs was also determined. The AngII treatment significantly increased BMP-2 expression levels and activated NF- $\kappa \mathrm{B}$. These effects were suppressed by treatment with pyrrolidine dithiocarbamate (PDTC) or probucol. Furthermore, the increased levels of MDA in the conditioned medium and the decrease in the total SOD activity caused by the AngII treatment were reversed by treatment with probucol or PDTC. Probucol downregulated the AngII-induced BMP-2 expression. These effects of probucol may be mediated by the inhibition of $\mathrm{NF}-\kappa \mathrm{B}$ activation.
\end{abstract}

\section{Introduction}

Previous studies have shown that bone morphogenetic protein-2 (BMP-2), a transforming growth factor- $\beta$ superfamily member cytokine, participates significantly in vascular development and pathophysiological processes $(1,2)$. Vascular endothelial and smooth muscle cells are a significant source of BMPs $(3,4)$.

Correspondence to: Jing-Hua Liu, Department of Cardiology, Beijing AnZhen Hospital, Capital Medical University, AnZhen Road 2, Chaoyang District, Beijing 100029, P.R. China

E-mail: mingzhang2003@yahoo.com.cn

*Contributed equally

Key words: bone morphogenetic protein-2, angiotensin II, probucol, pyrrolidine dithiocarbamate
BMP-2 induction in blood vessels may be related to oxidative stress, vascular inflammatory response, hyperglycemia and hyperlipidemia $(5,6)$. Angiotensin II (AngII), the main effector of the renin-angiotensin system, is essential for the regulation of blood pressure and is also involved in arterial wall remodeling $(7,8)$. The inhibition of the renin-angiotensin-aldosterone system has beneficial effects on endothelial functioning in animals and humans (9-11). The aim of this study was to investigate whether AngII induces BMP-2 expression. Furthermore, we also examined the effects of probucol, a cholesterol-lowering drug with potent antioxidative properties which attenuates atherosclerosis in animals and humans $(12,13)$, on the AngIIinduced BMP-2 expression.

\section{Materials and methods}

Human umbilical vein endothelial cell (HUVEC) culture and treatment. HUVECs and supplements, purchased from Cascade Biologics (Portland, OR, USA), were grown in Medium 200 with low serum growth supplement (LSGS) on polystyrene plates until $90 \%$ confluent. Non-adhering cells were poured off and the adhering cells were incubated at $37^{\circ} \mathrm{C}$ under an atmosphere of 5\% $\mathrm{CO}_{2}$ and $95 \%$ air. After 3-5 days, the cultures formed a confluent monolayer and were subcultured. The cells were used at passages 5-7. The cells were cultured at $1 \times 10^{6}$ cells $/ 25 \mathrm{~cm}^{2}$ flask and then were divided into 7 groups: a control group (treated with medium only); a probucol group (treated with $10 \mu \mathrm{mol} / \mathrm{l}$ probucol); a pyrrolidine dithiocarbamate (PDTC) group (treated with $15 \mu \mathrm{mol} / 1$ PDTC); 2 AngII groups (treated with 0.1 and $1.0 \mu \mathrm{mol} / 1$ AngII, respectively); an AngII + PDTC group (treated with $1.0 \mu \mathrm{mol} / 1$ AngII plus $15 \mu \mathrm{mol} / 1$ PDTC); and an AngII + probucol group (treated with $1.0 \mu \mathrm{mol} / 1$ AngII plus $10 \mu \mathrm{mol} / 1$ probucol). The combination treatment groups were pretreated with $15 \mu \mathrm{mol} / 1$ PDTC or $10 \mu \mathrm{mol} / 1$ probucol for $6 \mathrm{~h}$ prior to the administration of AngII.

BMP-2 mRNA expression by northern blot analysis. Total cellular RNA was isolated from the HUVECs using the TRIzol reagent (Invitrogen Life Technologies, Carlsbad, CA, USA). Northern blot analysis was performed as previously described (11). RNA blots were hybridized overnight at $57^{\circ} \mathrm{C}$ in a hybridization oven with $10^{6} \mathrm{cpm} / \mathrm{ml}$ of the $\left[\alpha-{ }^{32} \mathrm{P}\right]$ dATP-labeled oligonucleotide probes for BMP-2 or the cDNA for $\beta$-actin. The blots were then washed, air dried and exposed 
to Hyperfilm X-ray films (Amersham Biosciences, Piscataway, NJ, USA) at $-80^{\circ} \mathrm{C}$.

BMP-2 protein expression by western blotting. The plated cells were washed 3 times with PBS and lysed with $250 \mu 1$ lysis buffer $(50 \mathrm{mmol} / \mathrm{l}$ Tris- $\mathrm{HCl}, \mathrm{pH} 8.0,150 \mathrm{mmol} / 1 \mathrm{NaCl}, 0.02 \%$ sodium vanadate, $0.1 \%$ SDS, $0.5 \%$ deoxycholic acid, $100 \mu \mathrm{g} / \mathrm{ml} \mathrm{PMSF}$, $0.2 \mu \mathrm{g} / \mathrm{ml}$ leupeptin and $1 \% \mathrm{NP}-40)$. Samples were separated on a $12 \%$ SDS-PAGE gel and transferred onto PVDF filters by a wet transferring system (16). The membrane was blocked with Blotto-Tween (5\% non-fat milk and $0.05 \%$ Tween-20 in PBS) and incubated with the primary antibodies against BMP-2 and $\beta$-actin for $2 \mathrm{~h}$ at room temperature. Horseradish peroxidase-conjugated secondary $\operatorname{IgG}$ was then added and incubation was continued for $1 \mathrm{~h}$ at room temperature. The blots were developed using an enhanced chemiluminescence method (Zhongshan Biotechnology, Beijing, China).

Measurement of malondialdehyde (MDA) and BMP-2 concentrations in culture medium and total superoxide dismutase (SOD) activity in cell lysates. The concentrations of MDA were determined as thiobarbituric acid-reactive substances. The total activity of SOD was determined using the SOD Assay kit-WST according to the manufacturer's instructions. BMP-2 protein levels were measured by enzyme-linked immunosorbent assay (ELISA) according to the manufacturer's instructions. Each sample was assayed in duplicate. The intra-assay and interassay precision variability was $<8 \%$.

Effects of administering agents on cytoplasmic and nuclear levels of $N F-\kappa B ~ p 65$. The effects of various agents on the activation of NF- $\mathrm{kB}$ in HUVECs were determined using an assay kit from Active Motif (Carlsbad, CA, USA). This kit measures free $\mathrm{p} 65$, which is generated when NF- $\mathrm{kB}$ is activated. To obtain assay material, the cells were seeded at $1.0 \times 10^{6}$ cells $/ 25 \mathrm{~cm}^{2}$ flask. The cells were harvested $12 \mathrm{~h}$ after the addition of these agents. Cytoplasmic and nuclear cell fractions were collected using the reagents supplied in a nuclear extract kit (Active Motif). The cells were harvested by scraping and pelleted by centrifugation at $2,000 \mathrm{x}$ g at $4^{\circ} \mathrm{C}$ for $75 \mathrm{sec}$. The pelleted cells were resuspended in $200 \mu \mathrm{l}$ hypotonic buffer and incubated on ice for 15 min. Nonidet P-40 (Sigma, St. Louis, MO, USA), a solubilizing agent, was added and the cells were vortexed for $10 \mathrm{sec}$. The material was centrifuged for $45 \mathrm{~s}$ at $14,000 \mathrm{x} \mathrm{g}$ at $4^{\circ} \mathrm{C}$. The supernatant fluids (cytoplasmic fractions) were transferred to pre-chilled microcentrifuge tubes and stored at $-80^{\circ} \mathrm{C}$. The resulting nuclear pellets were resuspended in the lysis buffer supplied in the kit and then vortexed for $10 \mathrm{sec}$. The suspension was incubated for $30 \mathrm{~min}$ on ice on a rocking platform, vortexed for $30 \mathrm{sec}$ and then centrifuged at $14,000 \mathrm{x} \mathrm{g}$ for $10 \mathrm{~min}$ at $4^{\circ} \mathrm{C}$. The supernatant fluids (nuclear fractions) were transferred to pre-chilled microcentrifuge tubes and stored at $-80^{\circ} \mathrm{C}$. To assay the nuclear and cytoplasmic samples for amounts of p65, $20 \mu \mathrm{l}$ samples were added to the wells of a 96-well plate and coated with an oligonucleotide containing the NF- $\mathrm{kB}$ consensus binding site. The $\mathrm{p} 65$ subunit of the activated NF- $\kappa B$ contained in the cell extracts specifically binds to this oligonucleotide. The plate was incubated for $1 \mathrm{~h}$ at room temperature on a rocking platform. After washing, an antibody to $\mathrm{p} 65$ was added and the plate was incubated for $1 \mathrm{~h}$ at room

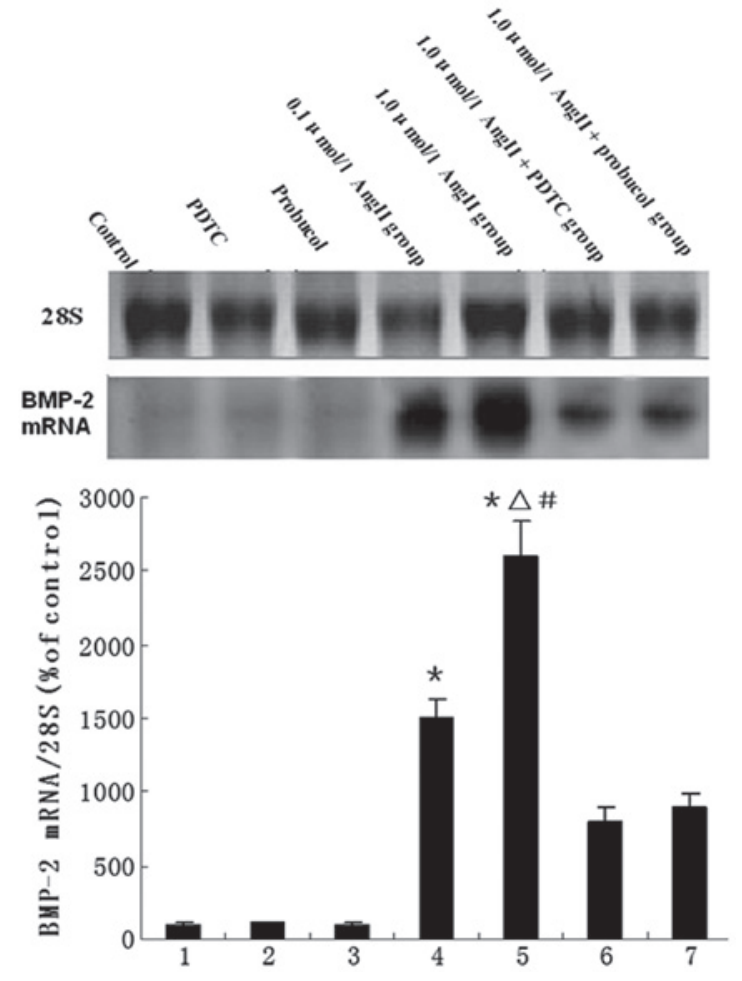

Figure 1. Northern blotting for evaluation of BMP-2 mRNA. The bar graph shows mean values ( \pm SEM) from the densitometric analysis of 7 treatment groups, $\mathrm{n}=8$ per group. The groups are: 1 , control; 2 , PDTC; 3 , probucol; 4, $0.1 \mu \mathrm{mol} / 1$ AngII; 5, $1.0 \mu \mathrm{mol} / 1$ AngII; 6, $1.0 \mu \mathrm{mol} / 1$ AngII + PDTC; and 7, $1.0 \mu \mathrm{mol} / 1 \mathrm{AngII}+$ probucol. ${ }^{*} \mathrm{P}<0.05$ vs. control group, ${ }^{\triangle} \mathrm{P}<0.05$ vs $1.0 \mu \mathrm{mol} / 1 \mathrm{AngII}+\mathrm{PDTC}$ group, ${ }^{~} \mathrm{P}<0.05$ vs. $1.0 \mu \mathrm{mol} / 1 \mathrm{AngII}+$ probucol group. BMP-2, bone morphogenetic protein-2; PDTC, pyrrolidine dithiocarbamate; AngII, angiotensin II.

temperature. The wells were then washed, an HRP-conjugated antibody was added and incubation was continued for $1 \mathrm{~h}$ at room temperature. After washing, a substrate solution was added to the wells and the plate was incubated at room temperature for $10 \mathrm{~min}$, protected from light. A stop solution $\left(2 \mathrm{~N} \mathrm{H}_{2} \mathrm{SO}_{4}\right.$ ) was added and the absorbance at $450 \mathrm{~nm}$ was read. The amounts of protein in the fractions were determined by a modification of the method of Lowry et al $(14,15)$. The results are expressed as $\mathrm{A}_{450} \mathrm{~nm} / \mathrm{mg}$ protein and expressed as a percentage (\%) of the control (value for cells exposed to control medium, set at $100 \%)$.

BMP-2 expression by immunohistochemistry. We also examined the expression of BMP-2 by immunohistochemical analysis. The treated HUVECs were grown on 6-well glass slides separately and fixed in acetone. After washing with PBS, the cells were incubated in a $1 \% \mathrm{H}_{2} \mathrm{O}_{2}$ solution at room temperature for $10 \mathrm{~min}$ to quench endogenous peroxidases. Non-specific binding was blocked with $5 \%$ normal horse serum at room temperature for $5 \mathrm{~min}$. The cells then were incubated with antiBMP-2 monoantibody (1:200 dilution) at $4^{\circ} \mathrm{C}$ overnight. After washing with PBS, the secondary antibody, biotinylated anti-rat, was added and the cells were incubated at room temperature for $1 \mathrm{~h}$. After washing with PBS, Vectastain reagent was added and the cells were incubated at room temperature for $10 \mathrm{~min}$. 3,3'-Diaminobenzidine was used as the chromagen. After $10 \mathrm{~min}$, the brown color signifying the presence of antigen 


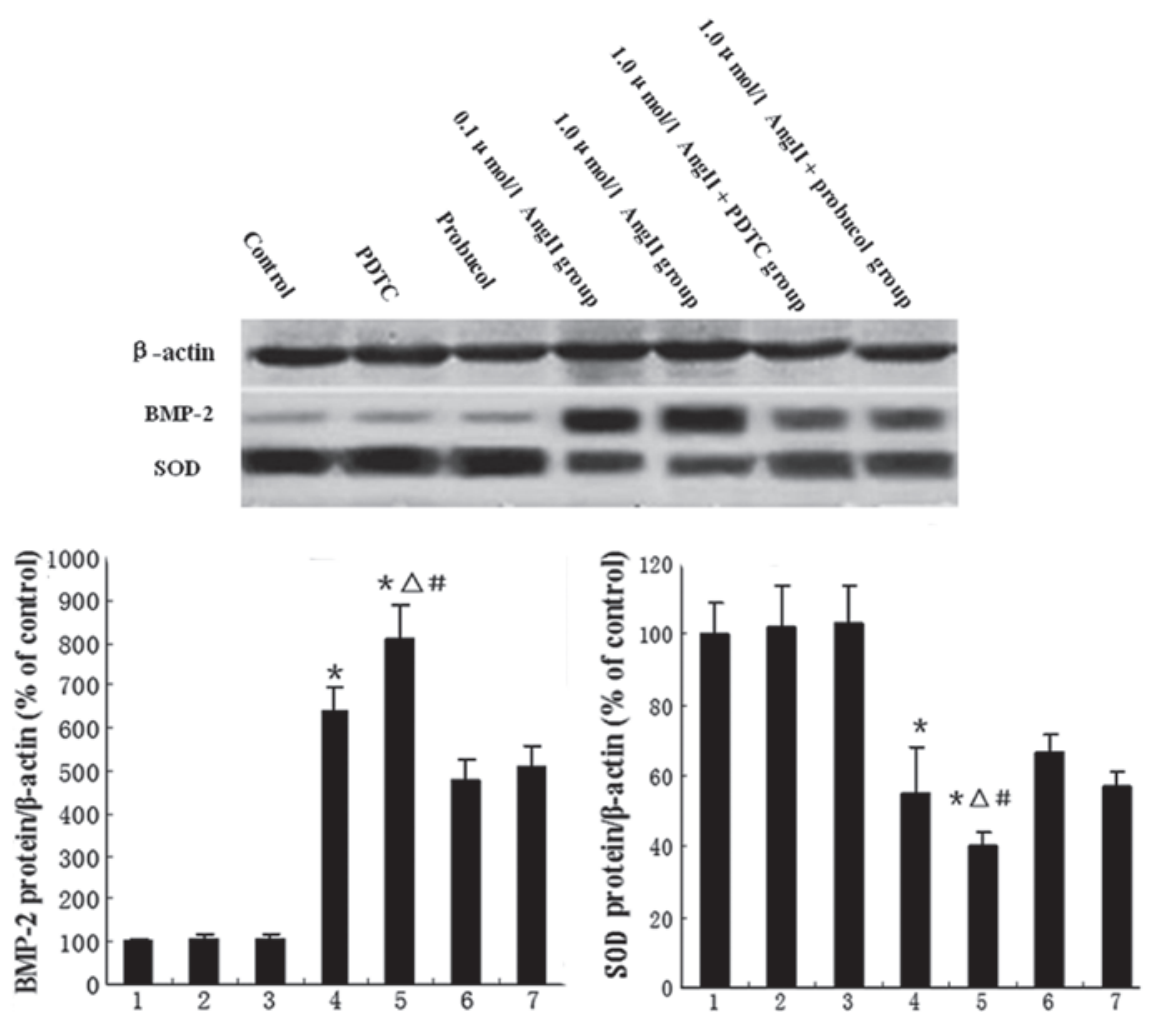

Figure 2. Western blotting for evaluation of BMP-2 and SOD proteins. The bar graphs show mean values $( \pm$ SEM) from the densitometric analysis of (A) BMP-2 expression and (B) SOD activity in the 7 treatment groups, $\mathrm{n}=8$ per group. 1, control; 2, PDTC; 3, probucol; $4,0.1 \mu \mathrm{mol} / 1 \mathrm{AngII} ; 5,1.0 \mu \mathrm{mol} / 1 \mathrm{AngII} ; 6,1.0 \mu \mathrm{mol} / 1$ AngII + PDTC; and 7, $1.0 \mu \mathrm{mol} / 1$ AngII + probucol groups. ${ }^{~} \mathrm{P}<0.05$ vs. control group, ${ }^{\wedge} \mathrm{P}<0.05$ vs. $1.0 \mu \mathrm{mol} / 1$ AngII $+\mathrm{PDTC}$ group, ${ }^{\#} \mathrm{P}<0.05$ vs. $1.0 \mu \mathrm{mol} / 1$ AngII + probucol group. BMP-2, bone morphogenetic protein-2; SOD, superoxide dismutase; PDTC, pyrrolidine dithiocarbamate; AngII, angiotensin II.

bound to antibodies was detected by light microscopy and images were captured at x100. Samples from each group were graded for histopathological changes and immunohistochemistry staining. The intensity of the immunostaining was graded from 0 (no staining) to degree $\mathrm{C}$ (maximum staining).

Statistical analysis. All data are presented as the means \pm SD. Multiple comparisons among groups were performed by one-way ANOVA analysis. $\mathrm{P}<0.05$ was considered to indicate a statistically significant result.

\section{Results}

Induction of BMP-2 expression in HUVECs. The mRNA levels of BMP-2 in the HUVECs following the various treatments are shown in Fig. 1. Compared with the control group, AngII treatment led to a significant increase in the expression levels of BMP-2 mRNA; however, administration of PDTC or probucol significantly downregulated the AngII-induced BMP-2 expression (Fig. 1). BMP-2 and CuZnSOD protein expression were also detected by western blot analysis. Our results showed that CuZnSOD protein expression was downregulated by AngII treatment, but this downregulation was partially reversed by probucol or PDTC treatment (Fig. 2A and B).

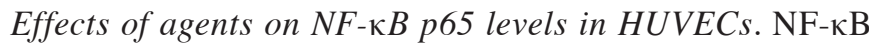
p65 activation was detected using immunohistochemistry and an assay kit from Active Motif. AngII caused a significant increase in nuclear p65 levels compared with those in
Table I. Effect of AngII on cytoplasmic and nuclear levels of $\mathrm{NF}-\mathrm{kB}$ p65.

\begin{tabular}{|c|c|c|}
\hline Groups & $\begin{array}{c}\text { Nuclear } \\
\text { NF- } \kappa B \text { p65 levels }\end{array}$ & $\begin{array}{c}\text { Cytoplasmic } \\
\text { NF-кB p65 levels }\end{array}$ \\
\hline Control & $205 \pm 22$ & $107 \pm 15$ \\
\hline $15 \mu \mathrm{mol} / 1 \mathrm{PDTC}$ & $210 \pm 19$ & $113 \pm 14$ \\
\hline $10 \mu \mathrm{mol} / \mathrm{l}$ probucol & $207 \pm 25$ & $108 \pm 13$ \\
\hline $0.1 \mu \mathrm{mol} / 1 \mathrm{AngII}$ & $529 \pm 49^{a}$ & $213 \pm 21^{a}$ \\
\hline $1.0 \mu \mathrm{mol} / \mathrm{l} \mathrm{AngII}$ & $1006 \pm 95^{\mathrm{a}, \mathrm{b}, \mathrm{c}}$ & $335 \pm 25^{\mathrm{a}, \mathrm{b}, \mathrm{c}}$ \\
\hline AngII + PDTC & $308 \pm 27$ & $190 \pm 20$ \\
\hline AngII + probucol & $312 \pm 28$ & $204 \pm 18$ \\
\hline
\end{tabular}

HUVECs $\left(1.0 \times 10^{6}\right)$ were incubated with $0,0.1$ or $1.0 \mu \mathrm{mol} / 1 \mathrm{AngII}$, $1.0 \mu \mathrm{mol} / \mathrm{l}$ AngII + PDTC $15 \mu \mathrm{mol} / 1$ or $1.0 \mu \mathrm{mol} / 1 \mathrm{AngII}+$ probucol $10 \mu \mathrm{mol} / \mathrm{l})$. Nuclear fractions were isolated and NF- $\kappa \mathrm{B}$ p65 levels were measured by ELISA. Results of multiple experiments, each with duplicate or triplicate determinations, are expressed as a percentage $(\%)$ of the non-stimulated control $\left(\mathrm{A}_{450} \mathrm{mg}\right.$ protein $) \pm$ standard deviation. Non-stimulated control levels were set at $100 \%$. Statistical analysis was performed by one-way ANOVA. ${ }^{\mathrm{a}} \mathrm{P}<0.05$ vs. control group, ${ }^{\mathrm{b}} \mathrm{P}<0.05$ vs. $1.0 \mu \mathrm{mol} / \mathrm{l}$ AngII + PDTC group, ${ }^{\mathrm{C}} \mathrm{P}<0.05$ vs. $1.0 \mu \mathrm{mol} / \mathrm{l}$ AngII + probucol group). AngII, angiotensin II; HUVECs, human umbilical vein endothelial cells; PDTC, pyrrolidine dithiocarbamate.

the control group, reaching a maximum increase of $\sim 5$-fold following $1.0 \mu \mathrm{mol} / 1 \mathrm{AngII}$ treatment, but this was decreased by the administration of PDTC or probucol. In the cytoplasm 

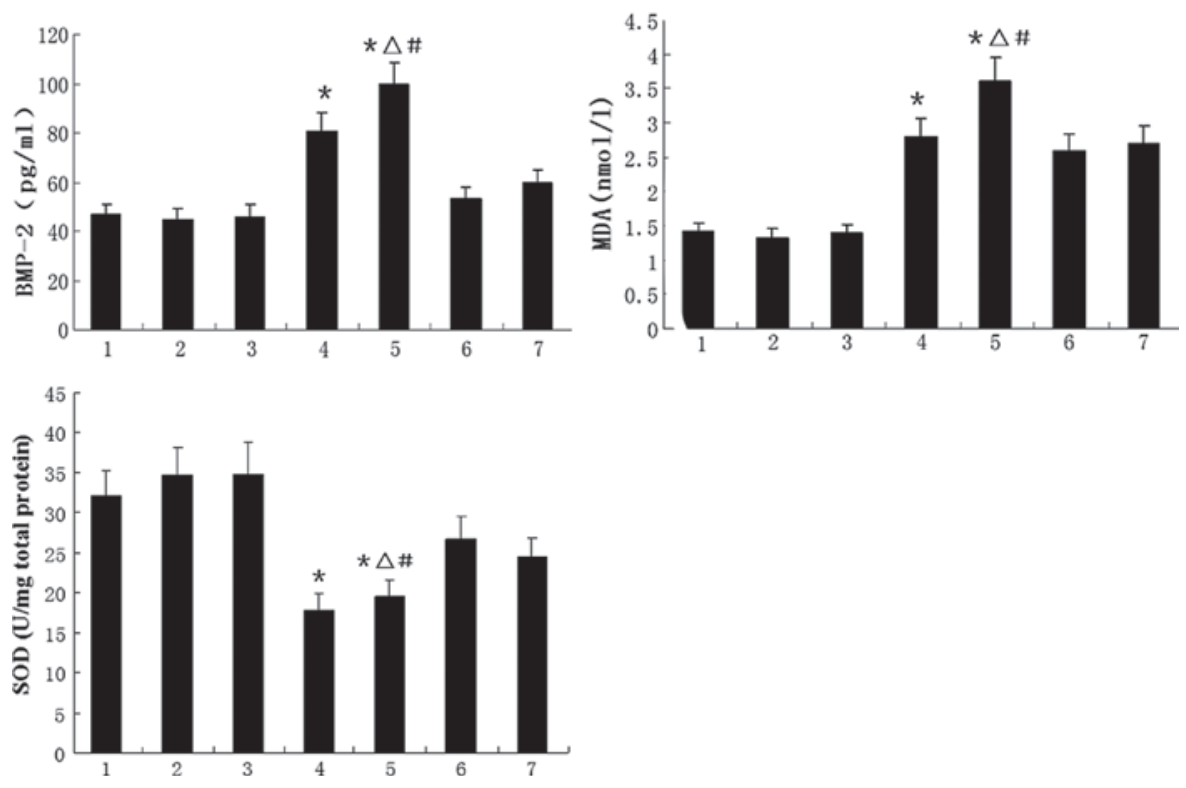

Figure 3. HUVECs were incubated with various stimuli and the (A) BMP-2 and (B) MDA levels and (C) total SOD activity of the cell cultures were analyzed. Data are the means \pm SD. 1, control; 2, PDTC; 3, probucol; 4, $0.1 \mu \mathrm{mol} / 1$ AngII; 5, $1.0 \mu \mathrm{mol} / 1 ; 6,1.0 \mu \mathrm{mol} / 1$ AngII + PDTC; and 7, $1.0 \mu \mathrm{mol} / 1$ AngII + probucol groups; $\mathrm{n}=8$ per treatment group. ${ }^{*} \mathrm{P}<0.05$ vs. control group, ${ }^{\wedge} \mathrm{P}<0.05$ vs. $1.0 \mu \mathrm{mol} / 1 \mathrm{AngII}+\mathrm{PDTC}$ group, ${ }^{\sharp \mathrm{P}}<0.05$ vs. $1.0 \mu \mathrm{mol} / 1$ AngII + probucol group. HUVECs, human umbilical vein endothelial cells; BMP-2, bone morphogenetic protein-2; MDA, malondialdehyde; SOD, superoxide dismutase; PDTC, pyrrolidine dithiocarbamate; AngII, angiotensin II.
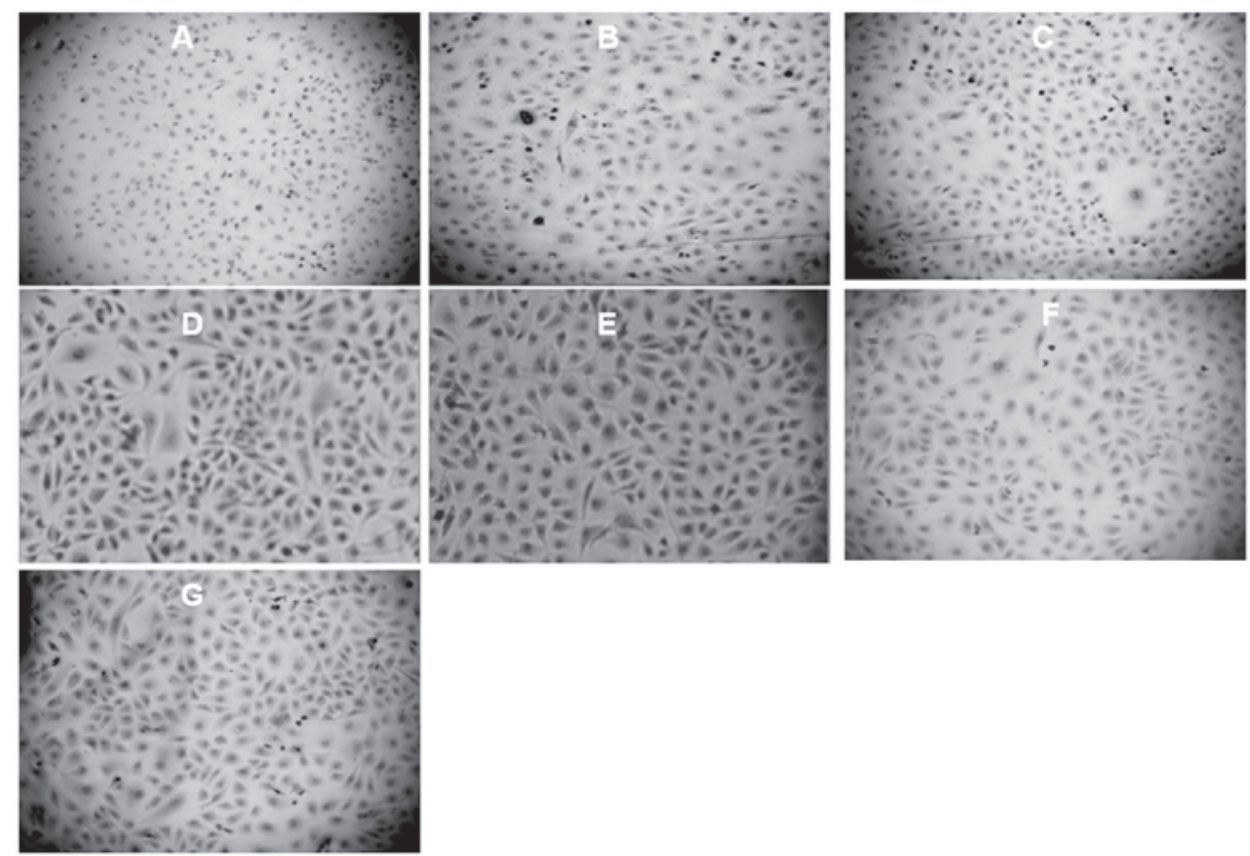

Figure 4. HUVECs were incubated with various stimuli and BMP-2 protein expression is shown. Representative slides of the immunohistochemical staining of BMP-2 protein in HUVECs (at x100). The images demonstrate a significantly higher staining of BMP-2 expression in the endochylema of the cells treated with AngII (D and E). Treatment with PDTC or probucol decreased the BMP-2 expression levels (F and G). (A) control; (B) PDTC; (C) probucol; (D) $0.1 \mu \mathrm{mol} / 1$ AngII; (E) $1.0 \mu \mathrm{mol} / 1$ AngII; (F) $1.0 \mu \mathrm{mol} / 1$ AngII + PDTC; and (G) $1.0 \mu \mathrm{mol} / 1$ AngII + probucol groups; $\mathrm{n}=4$ per treatment group. HUVECs, human umbilical vein endothelial cells; BMP-2, bone morphogenetic protein-2; PDTC, pyrrolidine dithiocarbamate; AngII, angiotensin II.

of these cells, we observed an increase in p65 levels following treatment with AngII, which also was inhibited by PDTC or probucol treatment (Table I).

Effect of AngII on total SOD activity and MDA and BMP-2 protein levels in the HUVEC culture. The effects of AngII on SOD activity and BMP-2 expression are shown in Fig. 3. Fig. 3A and B shows that AngII significantly increased the BMP-2 protein concentration in the supernatant and the MDA concentration in the HUVEC culture, but these increases were diminished by the administration of PDTC or probucol. Fig. 3C shows that AngII reduced the total SOD activity in 
the cultured HUVECs; however, this reduction was partially reversed by treatment with PDTC or probucol.

Immunohistochemistry for expression of BMP-2 protein. Representative slides of the immunohistochemical staining of BMP-2 protein in HUVECs (at x100) are shown in Fig. 4. Our results demonstrate a significantly higher staining of BMP-2 expression in the endochylema of HUVECs treated with AngII (Fig. 4D and E); however PDTC or probucol treatment inhibited the BMP-2 expression (Fig. 4F and G).

\section{Discussion}

BMP-2 is significantly involved in vascular development and pathophysiological processes. Mice genetically engineered to be deficient in BMP-2 die between days 7 and 10 of gestation due to cardiac defects prior to bone formation, which suggests the significance of BMP-2 in vascular development (16). AngII has been demonstrated to be critical in the initiation and progression of atherosclerosis. It stimulates atherosclerosis through various processes, including endothelial dysfunction, cellular proliferation and inflammation. AngII elicits the production of superoxide anion, a reactive oxygen species, from arterial endothelial cells and SMCs $(17,18)$. Importantly, there is evidence that AngII elicits significant increases in vascular $\mathrm{H}_{2} \mathrm{O}_{2}$ generation $(12,13)$. A study by Csiszar et al indicated that vascular BMP-2 expression is regulated by the $\mathrm{H}_{2} \mathrm{O}_{2}$-mediated activation of NF- $\kappa \mathrm{B}$ evoked by inflammatory stimuli or by high intravascular pressure (1); therefore, we hypothesized that AngII activates BMP-2 expression via NF- $\mathrm{B}$ activation. Indeed, our study demonstrated that the administration of AngII significantly increased BMP-2 expression. The hypothesis was also supported by the detection of NF- $\kappa \mathrm{B}$ activation. Our results revealed significantly higher levels of NF- $\mathrm{NB}$ p65 protein expression in the nuclei of the AngII-treated cells, which were reduced by treatment with PDTC or probucol. These findings suggest that the suppression of AngII-induced BMP-2 expression by probucol may involve the inhibition of $\mathrm{NF}-\kappa \mathrm{B}$ activation. The activation of NF- $\kappa \mathrm{B}$ may be an important signal transduction pathway affecting the AngII-induced increase in BMP-2 expression.

In the current study, we specially investigated probucol, a cholesterol-lowering drug with potent antioxidative properties and a clear radical-scavenging function (19). It was originally developed as a hypolipidemic drug (20), but interest has subsequently been focused on its potent antioxidant properties. Probucol has been shown to reduce the extent of atherosclerotic lesions in animal models and to inhibit atherosclerosis and restenosis following percutaneous transluminal coronary angioplasty $(21,22)$. Our study demonstrated that probucol inhibited the activation of NF- $\kappa \mathrm{B}$ by AngII in HUVECs, which is the likely mechanism responsible for the AngII-induced BMP-2 expression.

In order to evaluate the oxidative status of the HUVECs, we detected the activity of SOD together with the level of MDA, a well-known marker of oxidative stress. We observed that AngII increased MDA levels and decreased the total SOD activity. These findings indicated that excessive oxidative stress occurred during the AngII stimulation process. However, probucol treatment significantly reduced the MDA concentration and increased total SOD activity, suggesting that probucol had potent antioxidative properties, which is supported by a previous study (23). The protective effect of probucol against atherosclerosis may partly be due to its ability to lower MDA concentrations or increase antioxidant enzyme activities (24).

These findings further suggest that oxidative stress is a common mediator of such effects and indicate that the activation of $\mathrm{NF}-\kappa \mathrm{B}$ is a significant signal transduction pathway affecting the AngII-induced increase in BMP-2 expression. The AngII-induced inhibition of BMP-2 expression may contribute to the understanding of the initiation and progression of atherosclerosis and may lead to a new therapeutic strategy.

\section{Acknowledgements}

This study was funded by the Beijing Science and Technology New Star Program.

\section{References}

1. Csiszar A, Smith KE, Koller A, Kaley G, Edwards JG and Ungvari Z: Regulation of bone morphogenetic protein-2 expression in endothelial cells: role of nuclear factor-kappaB activation by tumor necrosis factor-alpha, $\mathrm{H}_{2} \mathrm{O}_{2}$, and high intravascular pressure. Circulation 111: 2364-2372, 2005.

2. Abedin M, Tintut Y and Demer LL: Vascular calcification: mechanisms and clinical ramifications. Arterioscler Thromb Vasc Biol 24: 1161-1170, 2004.

3. Shanahan CM, Cary NR, Metcalfe JC and Weissberg PL: High expression of genes for calcification-regulating proteins in human atherosclerotic plaques. J Clin Invest 93: 2393-2402, 1994.

4. Parhami F, Boström K, Watson K and Demer LL: Role of molecular regulation in vascular calcification. $\mathrm{J}$ Atheroscler Thromb 3: 90-94, 1996.

5. Hruska KA, Mathew S and Saab G : Bone morphogenetic proteins in vascular calcification. Circ Res 97: 105-114, 2005.

6. Boström KI, Jumabay M, Matveyenko A, Nicholas SB and Yao Y: Activation of vascular bone morphogenetic protein signaling in diabetes mellitus. Circ Res 108: 446-457, 2011.

7. Libby P, Ridker PM and Maseri A: Inflammation and Atherosclerosis. Circulation 105: 1135-1143, 2002.

8. Kranzhöfer R, Schmidt J, Pfeiffer CA, Hagl S, Libby P and Kübler W: Angiotensin induces inflammatory activation of human vascular smooth muscle cells. Arterioscler Thromb Vasc Biol 19: 1623-1629, 1999.

9. Tummala PE, Chen XL, Sundell CL, Laursen JB, Hammes CP, Alexander RW, Harrison DG and Medford RM: Angiotensin II induces vascular cell adhesion molecule-1 expression in rat vasculature: A potential link between the renin-angiotensin system and atherosclerosis. Circulation 100: 1223-1229, 1999.

10. Yung LM, Wong WT, Tian XY, Leung FP, Yung LH, Chen ZY, Yao X, Lau CW and Huang Y: Inhibition of renin-angiotensin system reverses endothelial dysfunction and oxidative stress in estrogen deficient rats. PLoS One 29: e17437, 2011.

11. Hernández-Presa M, Bustos C, Ortego M, Tuñon J, Renedo G, Ruiz-Ortega M and Egido J: Angiotensin-converting enzyme inhibition prevents arterial nuclear factor-kappaB activation, monocyte chemoattractant protein-1 expression, and macrophage infiltration in a rabbit model of early accelerated atherosclerosis. Circulation 95: 1532-1541, 1997.

12. Sawayama Y, Shimizu C, Maeda N, Tatsukawa M, Kinukawa N, Koyanagi S, Kashiwagi S and Hayashi J: Effects of probucol and pravastatin on common carotid atherosclerosis in patients with asymptomatic hypercholesterolemia: Fukuoka Atherosclerosis Trial (FAST). J Am Coll Cardiol 39: 610-616, 2002.

13. Mackness B, Durrington PN and Mackness MI: Lack of protection against oxidative modification of LDL by avian HDL. Biochem Biophys Res Commun 247: 443-446, 1998.

14. Lowry OH, Rosebrough NJ, Farr AL and Randall RJ: Protein measurement with the folin-phenol reagent. J Biol Chem 193: 265-275, 1951. 
15. Oyama VI and Eagle H: Measurement of cell growth in tissue culture with a phenol reagent (Folin-Ciocalteau). Proceedings of the Society of Experimental Biology and Medicine 91: 305-307, 1956.

16. Zhang $\mathrm{H}$ and Bradley A: Mice deficient for BMP2 are nonviable and have defects in amnion/chorion and cardiac development. Development 122: 2977-2986, 1996.

17. Suzuki Y, Ruiz-Ortega M, Lorenzo O, Ruperez M, Esteban V and Egido J: Inflammation and angiotensin II. Int J Biochem Cell Biol 35: 881-900, 2003.

18. Durante A, Peretto G, Laricchia A, Ancona F, Spartera M, Mangieri A and Cianflone D: Role of the renin-angiotensin-aldosterone system in the pathogenesis of atherosclerosis. Curr Pharm Des 18: 981-1004, 2012.

19. Tardif JC, Grégoire J and L'Allier PL: Prevention of restenosis with antioxidants: mechanisms and implications. Am J Cardiovasc Drugs 2: 323-334, 2002.

20. Buckley MMT, Goa KL, Price AH and Brogden RN: Probucol: a reappraisal of its pharmacological properties and therapeutic use in hypercholestecmia. Drugs 37: 761-800, 1989.
21. Tardif JC, Grégoire J, Schwartz L, Title L, Laramée L, Reeves F, Lespérance J, Bourassa MG, L'Allier PL, Glass M, Lambert J and Guertin MC; Canadian Antioxidant Restenosis Trial (CART-1) Investigators: Effects of AGI-1067 and probucol after percutaneous coronary interventions. Circulation 107: 552-558, 2003.

22. Kasai T, Miyauchi K, Kubota N, Kajimoto K, Amano A and Daida H: Probucol therapy improves long-term (>10-year) survival after complete revascularization: a propensity analysis. Atherosclerosis 220: 463-469, 2012.

23. Traverso N, Menini S, Maineri EP, Patriarca S, Odetti P, Cottalasso D, Marinari UM and Pronzato MA: Malondialdehyde, a lipoperoxidation-derived aldehyde, can bring about secondary oxidative damage to proteins. J Gerontol A Biol Sci Med Sci 59: B890-B895, 2004.

24. Memişoğulari R and Bakan E: Levels of ceruloplasmin, transferring, and lipid peroxidation in serum of patients with Type 2 diabetes mellitus. J Diabetes Complications 18: 193-197, 2004. 